\title{
The Effects of Mothers' Play Beliefs, Children's Gender and Home Play Frequency on Their Play Preferences
}

\author{
Jun Hee $\mathrm{Han}^{1}$, Na Ya Choi ${ }^{2}$ \\ Department of Early Childhood Education, Graduate School of Education The Catholic University, \\ Gyeonggi-do, Korea ${ }^{1}$ \\ Department of Child \& Family Studies, The Catholic University, Gyeonggi-do, Korea ${ }^{2}$ \\ 어머니의 놀이신념, 유아의 성별과 가정놀이빈도가 \\ 유아의 종류별 놀이선호에 미치는 영향 \\ 한준희 ${ }^{1}$, 최나야 ${ }^{2}$ \\ 가톨릭대학교 교육대학원 유아교육과 ${ }^{1}$, 가톨릭대학교 아동학과 ${ }^{2}$
}

Objective: The purpose of this study was to investigate the relationships among mothers' play beliefs, children's gender and home play frequency, and their preferences for three types of play.

Methods: Totally 256 mothers of 5-year-olds participated in the survey in metropolitan area. Data were analyzed with $t$-test, Pearson's correlations, and stepwise multi-regression using SPSS 22.0.

Results: First, boys and girls showed little difference in their home play experiences. Boys preferred active and rough play, while girls preferred quiet play. Second, mothers' play beliefs and children's home play frequency had partial correlations with children's play preferences. Third, predictors of children's play preferences were influenced by the types of play. Children's gender and mothers' play beliefs affected children's preference for active play. Only gender explained children's preference for rough play. Finally, children's gender, home play frequency, and mothers' play beliefs influence children's preference for quiet play.

Conclusion: In conclusion, gender is an important factor of children's play preferences, and mothers' play beliefs and children's home play frequency affect their preferences for a specific type of play.

Keywords: play beliefs, home play frequency, play preferences

\begin{abstract}
서론
유아는 놀이를 통해 세상을 탐색하고 경험하며 운동능력, 언 어·인지, 사회·정서적 측면에서 고르게 발달한다. 놀이는 유 아가 하는 일 중에서 가장 대표적이고 중요하여, 유아의 생활

Corresponding Author: Naya Choi, Department of Child \& Family Studies, The Catholic University of Korea, 43 Jibong-ro. Wonmi-go, Bucheon-si, Gyeonggi-do 14662, Korea

E-mail: choinaya@catholic.ac.kr
\end{abstract}

과 모든 측면에서 밀접하게 연관된다(M. S. Choi \& Kim, 2006; Pollock, Stewart, Law, Sahagian-Whalen, \& Toal, 1997). 따라서 유아에게 놀이의 중요성은 아무리 강조해도 지나치지 않다.

유아기 자녀를 둔 대부분의 부모들은 놀이가 유아의 전인 적 발달에 유익하므로, 놀이 기회를 풍부하게 제공해야 함을

(C)The Korean Association of Child Studies

This is an Open Access article distributed under the terms of the Creative Commons Attribution Non-Commercial License (http:// creativecommons.org/licenses/by-nc/4.0) which permits unrestricted noncommercial use, distribution, and reproduction in any medium, provided the original work is properly cited. 
알고 있다. 그러나 실제 육아에 있어서는 인지적 기술을 우선 시하여 조기교육, 특기교육 등을 중시하기 때문에 유아들의 학습 시간은 점차 늘어나고 있는 반면, 놀이 시간은 매우 부족 한 것으로 보인다. 유아의 여가시간에 대한 최근 연구(Korea Institute of Child Care and Education, 2014)에 따르면, 우리나라 유아의 여가시간 중 놀이 시간은 주중 합산 3 시간 10 분, 주말 합산 6 시간 18 분에 그쳤고, 유아들은 놀이 활동보다 미디어를 이용한 여가활동에 더 많이 참여하는 것으로 나타났다. 학습시 간의 증가와 놀이 시간의 부족은 신체활동, 스포츠 및 문화 참 여시간 등의 현저한 감소로 이어져, 유아들에게 긍정적인 경험 의 기회가 부족함이 문제시된다. 이러한 조사 결과는 학습 중 심 조기교육의 부정적인 측면으로, 놀이의 본질과 역할을 이해 하지 못하는 부모들이 있음을 보여주며(H. B. Lee, 2008), 놀이 에 대한 부모의 신념과 관련된 유아의 놀이 경험이 전인적 발 달에 미치는 영향에 대한 관심이 필요함을 보여준다.

그뿐만 아니라, 저출산 경향으로 유아 인구 자체가 줄어들 고 형제자매가 없는 유아의 수도 급증하였다. 이에 따라 유아 교육기관에서 보내는 시간을 제외하고는 놀이터나 다른 가정 을 오가며 함께 노는 유아기 또래들을 보기 힘든 현실이다. 유 아들은 놀이 시 발달수준이 비슷한 또래와 상호작용을 하면서 사회적 관계를 이해하고 사회적 기술과 사회적 행동양식이 발 달한다(Byun \& Chung, 2008). 그리고 가정에서 유아는 형제 자매와 오랜 시간 함께 지내면서 서로 놀이 상대자가 되어 상 호 영향을 주고받지만(Cicirelli, 1985), 외동아는 이러한 경험 이 제한된다.

이처럼 사회적 변화로 인하여 유아들이 발달에 필요한 놀 이를 충분히 경험하지 못하는 상황은 매우 심각하다고 본다. 그런데 유아들이 어떤 놀이를 얼마나 경험하고 있는지의 단순 한 변화 양상보다는 유아의 놀이에 영향을 주는 변인들을 입 체적으로 고려하는 연구를 설계함으로써 가정과 유아교육기 관에 보다 실질적인 도움을 줄 수 있을 것이다.

유아는 놀이에 직접 참여함으로서 기쁨, 만족, 즐거움과 성 취감뿐만 아니라 실패, 좌절, 소외와 거부 등을 경험하게 되며 자신만의 놀이 성향을 갖게 된다. 놀이 성향은 유아의 놀이 선 택에 영향을 미치고, 이는 다시 놀이선호로 이어진다. 놀이선 호는 유아가 놀이를 좋아하는 정도로, 유아가 놀이를 통해 느 끼는 만족감의 차이로도 나타나고 이후의 자발적인 놀이 참여 에도 영향을 준다. 유아의 놀이선호에 따라 개별 유아의 놀이 는 상당한 차이를 보이게 된다(Rogers et al., 1998).

놀이선호는 유아의 자발성을 존중하는 개념으로, 유아가 놀이를 할 때 교사나 부모의 지시에 따라 움직이는 것이 아니
라, 내면적인 동기 부여에 따라 놀이 종류를 자유롭게 선택하 고 자신의 본성, 생각, 흥미, 그리고 고유한 방식에 따라 놀이 의 내용과 의도를 결정하고 통제하는 것을 의미한다(Playwork Principles Scrutiny Group, 2005). 놀이선호는 유아가 특정 놀이 유형을 선택하게 만들고, 함께 참여할 집단을 결정하며, 유아 가 놀이에 더 몰입하여 확장된 즐거움을 느끼게 하므로 큰 의 미를 갖는다. 또한 유아의 놀이선호는 발달에 따른 변화를 겪 으면서도 안정적인 성향이 있어(Hong et al., 2009), 일회적인 놀이 행동에 비해 다른 변인들과의 관계를 살펴보는 데에 더 적합하다.

놀이선호는 유아가 '놀이' 자체를 좋아하는지의 불필요한 질문이 아니라, '어떤' 놀이를 좋아하는지의 유형론과 관련된 개념이다. 따라서 놀이선호 연구는 놀이의 유형이라는 틀 안 에서 이루어져야 한다. 유아의 놀이를 활동적 놀이, 거친 놀 이, 조용한 놀이로 구분하여 접근하는 방법은 성별에 따른 유 아의 대·소근육운동 발달을 인정하며, 유아들의 일상에서 대 표적으로 관찰할 수 있는 실제적인 놀이 양상을 구분해준다 (Finegan, Niccols, Zacher, \& Hood, 1991; K.-D. Park, 2005). 활 동적 놀이는 운동놀이를 포함하며 유아의 활동수준이 높아 실 내 · 외에서 신체의 대근육을 많이 활용하는 유형이다. 거친 놀이는 그에 비해 활동수준이 더욱 높으며 놀이상대와 힘을 겨루거나 큰 소리를 내며 노는 유형이다. 반면, 조용한 놀이는 주로 실내에서 놀잇감 또는 소근육, 상상력을 활용하여 정적 인 활동을 하는 유형이다(Seo, Lee, \& Park, 2009).

Miller와 Kuhaneck (2008)은 심층면담을 통해 7-11세 아동 의 놀이선호를 연구하였고 놀이 선택을 결정하는 네 요인으로 활동, 관계, 아동, 맥락을 제시하였다. 첫째, 활동의 수준은 움 직임의 양을 의미한다. 즉, 조용한 활동인지, 많은 움직임이 요 구되는 활동인지에 따라 아동의 놀이 선택 여부가 달라진다. 둘째, 함께 노는 사람, 셋째, 아동의 연령, 성별, 장애 여부 등의 개인적 특성, 넷째, 장소와 시간 등의 맥락이 놀이 선택에 영향 을 준다. 아동은 이러한 요인들의 영향에 따라 '재미있다'고 여 겨지는 놀이를 선택하게 되고, 그 때 느끼는 긍정적인 정서가 반복되면서 놀이 선택은 패턴, 즉, 선호가 되며, 아동은 숙달을 경험하게 된다. 이 이론은 더 어린 유아들에게도 적용될 수 있 을 것으로 보인다. 그리고 놀이선호가 단순히 활동을 선택하 는 것이 아니라 한 유아를 설명할 수 있는 중요한 특성이며, 발 달과 직결됨을 알 수 있다. 또한 위의 네 결정요인은 활동수준 이 서로 다른 놀이의 유형, 놀이참여자, 유아의 성별과 같은 개 인적 특성, 놀이가 일어나는 곳이 놀이선호에 큰 영향을 줄 수 있음을 시사한다. 따라서 본 연구에서는 이러한 요인들을 변 
인화하여 유아의 놀이선호와의 관계를 살펴보고자 한다.

놀이선호와 관련하여 가장 광범위하게 연구된 유아 개인 적 변인은 성별이다(Pellegrini \& Buorklund, 2004). 유아의 성 별은 놀이선호의 많은 부분을 결정하는 요인으로 보이므로, 먼저 놀이에서 나타나는 성차에 대해 살펴보고자 한다. 놀잇 감 측면에서 여아들은 인형을 좋아하고, 남아들은 자동차류 를 좋아하는 것이 대비된다(Serbin, Bohlin, \& Berlin, 1999). 또 한 쌓기놀이는 남아들이 좋아하고, 여아들은 역할놀이를 좋 아하는 것으로 보고된(Fromberg, 2002; M.-S. Kim, Yoo, Lee, \& Cho, 2010; Lindsey \& Mize, 2001; Pellegrini \& Perlmutter, 1989) 반면, 조형놀이는 남녀 유아 모두 선호하는 유형으로 보고되 었다(Fromberg, 2002; M.-S. Kim et al., 2010). 그리고 여아들 이 짝을 지어 놀면서 상호작용하는 것을 선호하는 반면에, 남 아가 여아보다 몸을 거칠게 움직이면서 노는 거친 신체놀이 를 더 많이 하는 경향이 반복적으로 나타났다(Benenson, 1993; Dipietro, 1981; Humphreys \& Smith, 1984; H. B. Lee, 2008; Si Ja Lee \& Lim, 1998; Sook Jae Lee, 1998; Pellegrini, 1989, 1992). 즉, 유아의 성별은 놀이 선택에 영향을 미쳐 놀이에서 성별 분리가 보편적으로 일어남을 알 수 있다(Colwell \& Lindsey, 2005; Fabes, Martin, \& Hanish, 2003; Martin \& Fabes, 2001). 따 라서 유아의 성별은 유형별 놀이를 선호하는 정도에 직접적인 영향을 미칠 것으로 예상된다. 그런데 위의 선행연구들은 놀 이의 유형을 종합적으로 함께 고려하지 않고, 대부분 특정 종 류의 개별적인 놀이나 놀잇감 활용 등에 초점을 맞추었으므 로, 유아들이 많이 하는 놀이의 전체적 패턴을 고려하여 유형 화할 필요가 있다.

유아의 놀이선호는 가정환경의 특성에 따라서도 많은 영향 을 받게 된다. 가정은 놀이가 이루어지는 최초의 환경으로, 그 중 인적 환경으로서의 어머니는 유아에게 주 양육자일 뿐만 아니라, 최초의, 그리고 최고의 놀이 상대자이다. 놀이에 대한 어머니의 인식과 태도에 따라 유아의 놀이 경험이 달라진다 (Chudacoff, 2007; J. H. Park \& Han, 2007). Fogle (2003)은 어머 니가 유아의 놀이에 대해 어떠한 신념 체계를 갖고 있는지가 유아의 놀이에 영향을 준다고 하였다. 대부분의 어머니들이 놀이를 가치 있는 것으로 인식하는 가운데(H.-S. Park, 2003), 어머니가 놀이를 중요하게 인식할수록 자녀의 놀이참여도와 만족도가 높아지는 것으로 나타났다(Y. S. Kim, 1991). 그리고 어머니의 놀이에 대한 인식에 따라 유아와 어머니의 놀이 상 호작용 빈도, 놀이 참여 유형, 유아의 놀이성 및 창의성 등이 달라지는 것도 밝혀졌다(E. A. Choi, 2005). 특히 어머니의 긍 정적인 놀이신념은 유아의 놀이성에 직접적으로 영향을 준다
(You \& Yoo, 2008). 또한 어머니가 놀이신념에 따라 선택하여 제공하는 구조화, 비구조화된 놀잇감(J. J. Kim, Kim, \& Shin, 2002)에 따라 생기는 놀이경험의 차이가 직·간접적으로 유아 의 놀이선호에 영향을 미칠 수 있다. 이상의 선행연구들은 어 머니의 놀이신념이 유아의 놀이에 영향을 줌을 보여주었지만, 유형별 놀이선호와의 관계를 직접적으로 살펴본 연구는 없다. 따라서 본 연구는 어머니의 놀이신념이 유아의 놀이선호에 영 향을 미치는지 알아보고자 한다.

한편, 부모가 놀이와 교육을 반의어 관계로 인식하여 교 육에 비해 놀이의 가치를 과소평가하는 경우도 많다(Eom, 2001). 부모들이 놀이 대신 학습에만 초점을 둔 구조화된 활 동을 제공함으로써 가정에서의 놀이 시간이 감소하는 경향 이 보고되었다(The Henry J. Kaiser Family Foundation, 2005; G. H. Park, 2011). 어머니가 놀이와 교육의 관계를 어떻게 인 식하는지에 따라 유아의 놀이 환경 및 시간에 차이가 생긴다 (Johnson, Cristie, \& Wardle, 2005; G. H Park, 2011). 어머니가 놀이와 교육의 관계를 부정적으로 인식하여 놀이가 유아의 학 습에 별 가치가 없고 학업 위주의 활동만을 추구하면 유아의 놀이를 제한할 수 있다. Isenberg와 Quisenberry (1988)도 유아 들이 학업 성취 압력을 받기 때문에 갈수록 놀이의 기회와 시 간에 제한을 겪는다고 지적하였다. 따라서 어머니의 놀이신념 이 유아의 가정놀이빈도와 관련될 것으로 예상할 수 있다.

그런데 유아가 가정에서 어떤 종류의 놀이를 많이 경험하 는지가 반드시 유아의 놀이선호를 그대로 보여주는 것은 아닐 수 있다. 각 가정의 놀이 환경이나 성인, 특히 어머니의 유도에 따라 여러 놀이의 빈도가 달라질 수 있기 때문이다. Jin과 Seo (2004)도 이러한 원인에 따라 유아의 놀이선호와 실제 참여하 는 놀이가 일치하지 않을 수 있음을 지적하였다. 따라서 가정 놀이빈도와 놀이선호를 구분해서 조사하고 관계를 알아볼 수 있다. 위에서 언급했듯이, 유아교육기관에서의 일과가 끝난 후 유아들이 가정에서 자유롭게 놀이를 할 수 있는 여건이 점 차 나빠지는 상황에서, 다양한 종류의 놀이를 얼마나 자주 하 고 있는지 구체적으로 살펴보고, 그 차이가 다른 변인들의 차 이를 가져오는지 규명하는 것은 의미가 있다.

이상에서 고찰해본 선행연구들을 종합해 볼 때, 유아의 놀 이선호에 영향을 미치는 변인으로 유아의 성별과 함께, 어머 니의 놀이신념과 유아의 가정놀이빈도를 꼽을 수 있다. 그러 나 이 변인들이 종합적인 놀이 유형에 대한 유아의 선호에 영 향을 미치는지 검증한 연구는 이루어지지 않았다. 또한 가정 환경을 구성하는 놀잇감에 대한 연구들은 많이 이루어졌지만, 유아의 가정놀이빈도를 양적으로 측정한 경우는 없었으므로, 
현재 우리사회에서 유아들이 가정에서 어느 정도의 놀이를 경 험하는지 살펴볼 필요가 있다. 무엇보다도, 유아의 놀이선호 에 영향을 미치는 변인을 규명한 연구가 부족하므로, 본 연구 에서는 만 5세 유아와 그들의 어머니를 대상으로 어머니의 놀 이신념과 유아의 가정놀이빈도가 유아의 놀이선호에 영향을 미치는지 살펴보고자 한다. 이를 통해 어머니의 놀이신념과 가정놀이의 중요성을 강조하고 이를 증진시킬 수 있는 방안을 위한 기초자료를 제공하고자 한다. 이를 위해 설정한 연구문 제는 다음과 같다.

\section{연구문제 1}

유아의 성별에 따라 유아의 가정놀이빈도와 놀이선호에 차이 가 있는가?

\section{연구문제 2}

어머니의 놀이신념, 유아의 가정놀이빈도와 놀이선호 간에 상관이 있는가?

\section{연구문제 3}

어머니의 놀이신념과 유아의 성별 및 가정놀이빈도는 유아의 종류별 놀이선호에 영향을 미치는가?

\section{연구방법}

\section{연구대상}

본 연구는 발달과정에서 충분한 놀이 경험을 하여 더 어린 연 령에 비해 상대적으로 뚜렷한 놀이선호를 형성한 만 5세 유아 들을 대상으로 하였다. 이에 따라 수도권 소재 유치원과 어린 이집 총 16 개 기관에 재원중인 만 5 세 유아의 어머니 292명을 조사자로 선정하여 질문지를 배부하였다. 배부한 질문지 중 271부(92.8\%)를 회수하였으나, 응답 누락 및 이중 기재 등의 불성실한 설문지 15 부를 제외한 256 부를 최종 분석하였다. 연 구 대상의 사회인구학적 특징은 Table 1 과 같다.

\section{연구 도구}

$$
\text { 어머니의 놀이신념 }
$$

Fogle (2003)이 제작하고 개정한(Fogle \& Mendez, 2006) 부모
놀이신념척도(The Parent Play Beliefs Scale [PPBS])를 번안한 척 도(H. B. Lee, 2008)와 번안 및 수정 후 요인분석을 실시한 척 도(You \& Yoo, 2008)를 동시에 참고하여 사용하였다. "놀이의 효용' 17 문항(예: “놀이는 우리 아이의 사고능력을 발달시키 는 데 도움이 된다.”), ‘놀이 참여의 중요성과 즐거움' 6 문항(예: “나에게 아이와 함께 노는 것은 중요하다.”)의 2 가지 하위 요 인으로 구성되어 있다. 즉, 놀이가 유아의 발달에 긍정적인 영 향을 미침을 인식하고, 어머니 스스로 놀이에 함께 참여하는 것을 중요하게 여기며 즐거워하는 태도를 측정한다. 총 23 문 항의 5점 Likert척도로, 전혀 그렇지 않다의 1점부터 매우 그렇 다의 5 점까지 측정하였다.

이와 함께 Fisher, Hirsh-Pasek, Golinkoff와 Gryfe (2008)의 Parents' and experts' perceptions of play를 번안한 G. H. Park (2011)의 척도로 어머니의 놀이신념 측정을 보완하였다. "놀이 의 개념 인식'(22문항; 예: "다음 내용이 놀이라고 생각하십니 까?", "가정에서 유아용 의자나 소파, 그릇, 수저, 청진기, 주사 기 등을 가지고 활동하는 것”)은 어머니가 다양한 활동을 놀이 로 개념화하는 정도를 측정하며, '놀이의 교육적 가치 인식'(21 문항; 예: "다음 내용이 유아에게 교육적 가치가 있다고 생각하 십니까?”, “집 안이나 집 주변에서 찾은 실제 사물을 놀잇감으 로 사용하여 활동하는 것”)은 놀이 경험에 대해 교육적으로 가 치 있다고 여기는 정도를 측정한다. 즉, 총 43 문항이며, 원척도 는 4점 Likert척도이나 요인 간 통합을 위해 절대 그렇지 않다(1 점)부터 매우 그렇다(5점)까지 5점 방식으로 측정하였다.

네 요인의 점수 및 총점이 높을수록 유아의 놀이를 인정하 고 지원하는 어머니의 신념이 강함을 의미한다. 문항 내적 일 치도(Cronbach's $\alpha$ )는 놀이의 효용 .85. 놀이 참여의 중요성과 즐거움 .75 , 놀이의 개념 .95 , 놀이의 교육적 가치 .93 , 어머니 의 놀이신념 전체 .96으로 나타났다.

\section{가정놀이빈도}

Fisher, Hirsh-Pasek, Golinkoff와 Gryfe (2008)의 연구에서 사용 한 질문지를 번안한 G. H. Park (2011)의 척도를 일부 수정·보 완하여 사용하였다. '놀이 빈도'는 가정에서 유아가 특정 놀이 (예: "가정에서 장난감 자동차, 비행기, 기차, 버스를 사용하여 활동하기”)를 '얼마나 자주 하는가'를 측정하는 총 23 문항의 7 점 Likert 척도로, 거의 안 한다(1점)부터 거의 매일 한다(7점) 까지 중에서 응답하도록 하였다. 자유놀이 14 문항(장난감/실 물놀잇감 놀이, 가장놀이, 블록놀이, 미술놀이, 탐구놀이, 실외 놀이, 협동놀이)과 구조화된 놀이(학업기반 놀이, 전자놀이) 9 
Table 1

Demographic Characteristics of the Participants

\begin{tabular}{|c|c|c|}
\hline \multirow[b]{2}{*}{ Variable } & \multicolumn{2}{|c|}{ Frequency } \\
\hline & $n$ & $\%$ \\
\hline \multicolumn{3}{|l|}{ Children's gender } \\
\hline Boys & 112 & 43.8 \\
\hline Girls & 144 & 56.3 \\
\hline \multicolumn{3}{|l|}{ Children's birth order } \\
\hline First & 143 & 55.9 \\
\hline Second & 92 & 35.9 \\
\hline Third & 17 & 6.6 \\
\hline Fourth or above & 4 & 1.6 \\
\hline \multicolumn{3}{|l|}{ Mothers' age (years) } \\
\hline Up to 30 & 6 & 2.3 \\
\hline $31-35$ & 47 & 18.4 \\
\hline $36-40$ & 133 & 52.0 \\
\hline $41-45$ & 61 & 23.8 \\
\hline 46 and above & 9 & 3.5 \\
\hline \multicolumn{3}{|l|}{ Mothers' education } \\
\hline High-school graduated & 61 & 23.8 \\
\hline Junior college graduated & 90 & 35.2 \\
\hline University graduated & 91 & 35.5 \\
\hline Master's degree or more & 14 & 5.5 \\
\hline \multicolumn{3}{|l|}{ Mothers' job status } \\
\hline Employed & 149 & 58.2 \\
\hline Unemployed & 107 & 41.8 \\
\hline \multicolumn{3}{|c|}{ Monthly income (Million Korean won) } \\
\hline Less than 200 & 10 & 3.9 \\
\hline $200-299$ & 41 & 16.0 \\
\hline $300-399$ & 59 & 23.0 \\
\hline $400-499$ & 66 & 25.8 \\
\hline 500 or more & 80 & 31.3 \\
\hline
\end{tabular}

Note. $N=256$.

문항으로 구성되어 있다. 23문항의 척도에 대한 문항 내적 일 치도(Cronbach's $\alpha$ )는 .84로 나타났다.

놀이선호

캐나다에서 개발된 부모용 유아놀이선호 척도(Finegan et al., 1991)를 Seo 등(2009)이 우리나라에 적용하여 개념적, 통계적 으로 타당화한 척도를 수정 · 보완하여 사용하였다. 이 척도는 유아들의 활동수준과 성별, 연령을 반영하여 부모가 놀이선 호를 간단하고 객관적으로 검사할 수 있는 장점을 지니고 있
다. '활동적 놀이' 8 문항, '거친 놀이' 4 문항, '조용한 놀이' 3 문 항의 3요인으로 이루어져 있고, 유아가 각 문항에 묘사된 특 징의 놀이를 얼마나 좋아하는지 묻는다. 예를 들면, 활동적 놀 이는 “신체적으로 용감하고 대담하게 놀이를 좋아한다.", 거 친 놀이는 “친구들과 힘을 겨루는 놀이를 좋아한다.”, 조용한 놀이는 “조용한 테이블 활동을 좋아한다.” 등이다. 즉, 가정놀 이빈도는 ‘미술놀이'처럼 구체적인 명칭의 놀이 종류로 구분 되어 있는 반면, 놀이선호 척도는 좋아하는 놀이의 특징을 세 가지로 유형화한 것이다. 총 15 문항의 5점 Likert척도로, 유아 가 각 놀이를 좋아하는 정도를 전혀 그렇지 않다(1점)부터 매 우 그렇다(5점)까지 측정하였다. 조사 후 분석을 통해 활동적 놀이와 거친 놀이의 구분이 어렵거나 신뢰도가 낮은 4 문항을 제외하고(삭제 문항: 활동적 놀이: “공을 잘 던짐”, “방망이를 사용한 놀이를 좋아함"; 거친 놀이: “활동적이고 거친 친구 좋 아함" “친구들과 활동적, 활발한 놀이를 좋아함”), 활동적 놀 이 6 문항, 거친 놀이 2 문항, 조용한 놀이 3 문항의 11 문항을 사 용하였다. 신뢰도(Cronbach's $\alpha$ )는 활동적 놀이 .91, 거친놀이 .79 , 조용한 놀이 .67로 나타났다.

\section{연구 절차}

수도권 소재 유치원과 어린이집에 재원중인 만 5 세 유아를 둔 어머니의 연구 참여 동의를 얻어 질문지 조사를 실시하였다. 어머니의 놀이신념, 유아의 가정놀이빈도와 놀이선호에 대한 질문지를 유아교육기관을 통하여 각 가정으로 배부하고 약 일 주일 후 연구자가 방문하여 회수하였다.

\section{자료 분석}

본 연구에서 수집된 자료는 SPSS 22.0 (IBM Co., Armonk, NY) 프로그램을 사용하여 통계 분석하였다. 구체적으로, 연구 대 상의 일반적 특성을 파악하기 위해 빈도, 백분율, 평균, 표준 편차를 산출하였으며, 검사 도구의 신뢰도를 파악하기 위해 Cronbach's $\alpha$ 값을 산출하였다. 유아의 성별에 따른 어머니의 놀이신념, 유아의 가정놀이빈도, 유아의 놀이선호의 차이가 있는지 알아보기 위해 $t$-검정을 실시하였다. 그리고 어머니의 놀이신념, 유아의 가정놀이빈도, 놀이선호 간의 관계를 알아 보기 위해 Pesrson의 상관분석을 실시하였다. 마지막으로, 어 머니의 놀이신념과 유아의 가정놀이빈도가 종류별 놀이선호 에 미치는 상대적 영향력을 살펴보기 위해 단계적 회귀분석을 실시하였다. 
Table 2

Differences in Play Frequency by Child's Gender

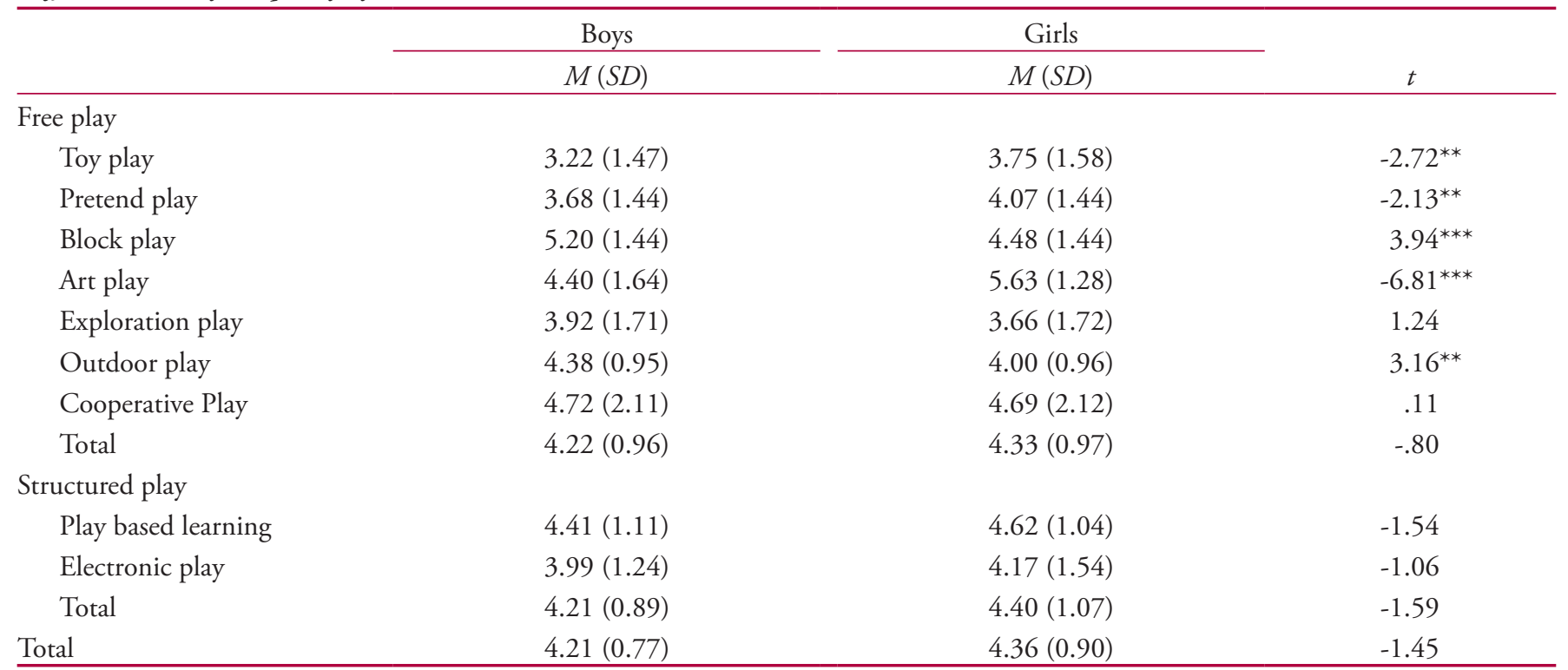

Note. $N=256$ (boys $=112$, girls $=144)$.

${ }^{* *} p<.01 .{ }^{* * *} p<.001$.

Table 3

Differences in Play Preferences by Child's Gender

\begin{tabular}{lcccc}
\hline & Boys & Girls & \multicolumn{1}{c}{$t$} \\
\cline { 2 - 3 } Active play & $M(S D)$ & $3(S D)$ & $3.25^{* *}$ \\
Rough play & $3.97(0.78)$ & $3.65(0.82)$ & $7.09^{* * *}$ \\
Quiet play & $3.04(0.97)$ & $2.19(0.94)$ & $-7.54^{* * *}$ \\
Total & $3.02(0.84)$ & $3.75(0.69)$ & $2.40^{* * *}$ \\
\hline
\end{tabular}

Note. $N=256$ (boys = 112, girls = 144).

${ }^{* *} p<.01 .{ }^{* * *} p<.001$.

\section{연구결과}

\section{유아의 성별에 따른 가정놀이빈도와 놀이선 호의 차이}

\section{유아의 성별에 따른 가정놀이빈도 차이}

유아의 가정놀이빈도에 성차가 있는지 알아보기 위해 $t$-검정 을 실시한 결과는 Table 2 와 같다. 여아가 4.15, 남아가 4.00으 로 총점에서 여아가 다소 높은 점수를 보였으나, 통계적으로 유의한 차이는 아니었다. 본 연구에서 활용한 7점 척도에서 4 점은 주 1 회 정도의 빈도를 의미하므로, 유아들이 가정에서 각 놀이를 1 주일에 평균 1 번꼴로 한다고 볼 수 있다.
그러나 하위 요인인 자유놀이 중에서 몇 가지의 활동에 대 해서는 놀이빈도에서 성차가 발견되었다. 장난감/실물놀잇 감 놀이 $(t=-2.72, p<.01)$, 가장놀이 $(t=-2.13, p<.01)$, 미술놀 이 $(t=-6.81, p<.001)$ 는 여아들이 더 자주하는 반면, 블록놀이 $(t=3.94, p<.001)$ 와 실외놀이 $(t=3.16, p<.01)$ 는 남아들이 유 의하게 더 자주하는 것으로 나타났다.

\section{유아의 성별에 따른 놀이선호 차이}

유아의 놀이선호에 성차가 있는지 알아보기 위해 $t$-검정을 실 시한 결과는 Table 3 과 같다. 놀이선호의 하위 요인인 활동적 놀이 $(t=3.25, p<.001)$ 에서 남아 $(M=3.97, S D=0.78)$ 가 여아 $(M=3.65, S D=0.82)$ 보다 높은 선호를 보였고, 거친 놀이 $(t=$ 
$7.09, p<.001)$ 역시 남아 $(M=3.04, S D=0.97)$ 가 여아 $(M=2.19$, $S D=0.94)$ 보다 선호가 더 높았다. 반면, 조용한 놀이 $(t=-7.54$, $p<.001)$ 는 여아 $(M=3.75, S D=0.69)$ 가 남아 $(M=3.02, S D=$ $0.84)$ 보다 더 높은 선호를 보였다. 즉, 놀이를 좋아하는 정도가 유아의 성별에 따라 달라, 놀이의 유형에 따라 성차가 분명하 게 나타났다. 남아는 활동적이고 거친 놀이를 더 좋아하고, 여 아는 조용한 놀이를 좋아함을 보여주었다.

\section{어머니의 놀이신념, 유아의 가정놀이빈도와 놀이선호 간의 관계}

회귀분석의 가능성을 탐색해보고, 어머니의 놀이신념, 유아의 가정놀이빈도와 놀이선호 간의 전반적인 관계를 알아보기 위 해 변인들의 하위 요인 수준에서 Pearson의 적률상관계수를 산 출하였다. 상관분석 결과는 Table 4에 제시하였다.

유아의 놀이선호는 어머니의 놀이신념 $(r=.17, p<.01)$ 과 상관이 있으나, 가정놀이빈도와는 상관이 없는 것으로 나타났 다. 그러나 놀이선호는 하위 유형별로 관련 있는 변인이 다를 가능성이 크므로, 하위 요인별로 상관을 살펴보았다.

먼저, 활동적 놀이에 대한 유아의 선호는 어머니의 놀이신 념 전체와 상관을 보였고 $(r=.24, p<.001)$, 놀이신념의 4 개 하 위 요인들과도 모두 상관이 있었다. 상관계수는 각각 다음과 같았다. 어머니의 놀이의 효용 인식 $(r=.19, p<.01)$; 놀이 참 여 중요성과 즐거움 인식 $(r=.22, p<.001)$; 놀이 개념 인식 $(r=$ $.15, p<.05)$; 놀이의 교육적 가치 인식 $(r=.18, p<.01)$. 반면, 활동적 놀이에 대한 유아의 선호는 가정놀이빈도의 모든 요인 들과는 유의한 상관이 없었다. 이를 통해 어머니의 놀이신념 이 유아가 활동적 놀이를 좋아하는 정도와 관련이 있는 반면, 유아의 가정놀이빈도와 활동적 놀이선호 간에는 관계가 없음 을 알 수 있다. 즉, 어머니가 유아의 놀이의 중요성과 효용성을 인지하고 놀이에 대해 개방적 태도를 취할 때, 유아가 활동적 놀이를 선호하게 된다고 예측할 수 있다.

다음으로, 거친 놀이선호는 어머니의 놀이신념 하위 요인, 유아의 가정놀이빈도 하위 요인과 전혀 상관을 보이지 않았다. 즉, 어머니의 놀이신념과 유아의 가정놀이빈도는 유아가 거친 놀이를 선호하는 것과 관련이 없었다. 다만 활동적 놀이를 선 호하는 정도와만 높은 정적 상관을 보여 $(r=.54, p<.001)$, 거친 놀이와 활동적 놀이 간에 유사성이 높음을 보여주었다.

마지막으로, 조용한 놀이선호는 가정놀이빈도의 총합 $(r=$ $.21, p<.01)$ 및 자유놀이빈도 $(r=.27, p<.001)$ 와 상관을 보였 다. 구조화된 놀이의 빈도와는 상관을 보이지 않았으므로, 전
체 놀이빈도와 상관이 나타난 것도 자유놀이빈도를 설명하는 것이라 볼 수 있다. 또한 조용한 놀이선호는 어머니의 놀이 효 용 인식 $(r=.15, p<.05)$ 및 전체 놀이신념 $(r=.15, p<.05)$ 과도 약한 상관을 나타났다. 이를 통해 유아가 가정에서 놀이경험 을 많이 하는 것과 어머니가 놀이의 효과를 강하게 인식하는 것, 그리고 유아가 조용한 놀이를 선호하는 것 간에 관련이 있 음을 알 수 있다. 또한 유아가 조용한 놀이를 선호하는 것은 거 친 놀이를 선호하는 것과 부적 상관을 보여 $(r=-.33, p<.001)$, 이 두 유형의 놀이를 선호하는 것은 병립하지 않음을 시사하 였다. 반면, 활동적 놀이에 대한 선호와의 상관계수도 부적 방 향이나, 유의한 관계는 나타나지 않았다.

\section{어머니의 놀이신념, 유아의 가정놀이빈도가 놀이선호에 미치는 상대적 영향}

위에서 변인들 간의 부분적인 상관을 발견하였으므로, 여기 에서 더 나아가 영향력을 검증하고자 회귀분석을 실시하고 자 하였다. 어머니의 놀이신념, 유아의 가정놀이빈도가 유아 의 놀이선호에 미치는 영향력 분석을 위한 기본 가정의 만족 여부를 파악하기 위해 VIF 계수와 Durbin-Watson 계수를 조 사한 결과, VIF 지수는 $1.00 \sim 3.73$ 점으로 10 보다 작아 두 변인 간에 다중공선성에 문제가 없는 것으로 볼 수 있으며, DurbinWatson 계수는 $1.88 \sim 2.12$ 로 잔차 간 자기상관이 없는 것으로 판단되었다. 그리고 위의 결과에서 유아의 유형별 놀이선호의 성차가 발견되었으므로, 회귀분석시 유아의 성별을 가장 먼저 투입하여 통제한 후, 다른 변인들의 추가적인 영향력을 파악 하고자 하였다. 한편, 상관분석시, 독립변인인 어머니의 놀이 신념과 유아의 가정놀이빈도의 하위 요인들 간에 높은 수준의 정적 상관이 나타났다. 어머니의 놀이신념을 구성하는 네 요 인 간에는 상관계수가 .23 .84 ( $p$ < .001)였고, 자유놀이빈도 와 구조화놀이빈도 간의 상관계수는 .48 ( $p$ <.001)이었다. 특 히 높은 상관수치는 어머니의 놀이 개념 인식과 놀이의 교육 적 가치 인식 간에 나타났는데 $(r=.84)$, 이는 측정 방식상, 동일 한 활동을 제시하면서 그 활동을 놀이로 여기는지, 그리고 그 활동의 교육적 가치는 어느 정도라고 여기는지를 질문하였기 때문으로 보인다. 비록 다중공선성 통계치에 문제가 없다하더 라도 요인 간 상관이 높은 것이 문제시될 수 있으며, 변인을 구 성하는 하위 요인들의 상대적인 영향력이 아닌 변인의 영향력 자체를 살펴보고자 하므로 회귀분석을 위해서는 두 변인의 총 점을 이용하였다. 
Table 4

Relationships Among Mothers' Play Beliefs, Children's Home Play Frequency, and Children's Play Preferences

\begin{tabular}{|c|c|c|c|c|c|c|c|c|c|c|c|}
\hline Variables & 1 & 2 & 3 & 4 & 5 & 6 & 7 & 8 & 9 & 10 & 11 \\
\hline 1. Benefits of play & - & & & & & & & & & & \\
\hline $\begin{array}{l}\text { 2. Importance of and enjoyment in } \\
\text { play participation }\end{array}$ & $.61^{* * *}$ & - & & & & & & & & & \\
\hline 3. Concept of play & $.47^{* * *}$ & $.23^{* * *}$ & - & & & & & & & & \\
\hline 4. Educational value of play & $.53^{* * *}$ & $.30^{* * *}$ & $.84^{* * *}$ & - & & & & & & & \\
\hline 5. Play beliefs total & $.82^{* * *}$ & $.71^{* * *}$ & $.80^{* * *}$ & $.83^{* * *}$ & - & & & & & & \\
\hline 7. Structured play frequency & .01 & .08 & $-.15^{*}$ & -.20 & -.02 & $.48^{* * *}$ & - & & & & \\
\hline 8. Play frequency total & $.13^{* *}$ & $.16^{*}$ & -.03 & .07 & .10 & .86 & $.86^{* * *}$ & - & & & \\
\hline 9. Preference for Active play & $.19^{* *}$ & $.22^{* * *}$ & $.15^{*}$ & $.18^{* *}$ & $.24^{* * *}$ & .03 & .03 & .03 & - & & \\
\hline 10. Preference for Rough play & -.08 & -.04 & -.03 & .00 & -.05 & .05 & .07 & .07 & $.54^{* * *}$ & - & \\
\hline
\end{tabular}

Note. $N=256$.

${ }^{*} p<.05 .{ }^{* *} p<.01 .{ }^{* * *} p<.001$.

Table 5

Stepwise Regression Analyses of Mothers' Play Beliefs, Children's Gender and Play Frequency on Children's Preference for Active Play

\begin{tabular}{|c|c|c|c|c|}
\hline & \multicolumn{4}{|c|}{ Preference for active play } \\
\hline & \multicolumn{2}{|c|}{ Model I } & \multicolumn{2}{|c|}{ Model II } \\
\hline & $\mathrm{B}$ & $\beta$ & $\mathrm{B}$ & $\beta$ \\
\hline Mothers' play belief & & & .58 & $.24^{* * *}$ \\
\hline$F$ & \multicolumn{2}{|c|}{$10.55^{* *}$} & \multicolumn{2}{|c|}{$13.31^{* * *}$} \\
\hline$\Delta R^{2}$ & & & \multicolumn{2}{|c|}{.06} \\
\hline Durbin-Watson & \multicolumn{4}{|c|}{1.88} \\
\hline
\end{tabular}

Note. $N=256$. dummy variables: boys $=0$, girls $=1$.

${ }^{* *} p<.01 .{ }^{* * *} p<.001$.

어머니의 놀이신념, 유아의 성별과 가정놀이빈 도가 유아의 활동적 놀이선호에 미치는 영향력

어머니의 놀이신념, 유아의 성별과 가정놀이빈도가 유아의 활 동적 놀이선호에 영향을 미치는지 살펴보기 위해 단계적 회귀 분석을 실시한 결과는 Table 5와 같다.

유아의 활동적 놀이선호에 영향을 미치는 변인으로는 어머 니 놀이신념 $(\beta=.24, p<.001)$ 과 유아의 성별 $(\beta=-.20, p<.01)$ 이 확인되었다. 유아의 성별이 $4 \%$ 의 설명력을 지니고, 어머 니의 놀이신념이 추가됨으로써 설명력이 $6 \%$ 증가하여 전체 $10 \%$ 의 설명력을 보였다. 즉, 어머니의 놀이신념, 그리고 사회
인구학적 변인인 유아의 성별이 활동적 놀이를 선호하는 정도 에 영향을 미치는 것으로 나타났다. 이 결과를 통해 남아의 활 동적 놀이 선호가 여아에 비해 강하며, 어머니의 놀이의 가치 를 인정하고 스스로 유아의 놀이에 즐겁게 참여할 때 유아의 활동적 놀이선호가 강해짐을 알 수 있다.

어머니의 놀이신념, 유아의 성별과 가정놀이빈 도가 유아의 거친 놀이선호에 미치는 영향력

어머니의 놀이신념과 유아의 성별 및 가정놀이빈도가 거친 놀 이선호에 영향을 미치는지 살펴보기 위해 회귀분석을 실시한 
Table 6

Stepwise Regression Analyses of Mothers' Play Beliefs, Children's Gender and Play Frequency on Children's Preference for Rough Play

\begin{tabular}{lcc}
\hline & \multicolumn{2}{c}{ Preference for rough play } \\
\cline { 2 - 3 } & \multicolumn{3}{c}{ Model I } \\
\cline { 2 - 3 } & \multicolumn{3}{c}{$B$} & $\beta$ \\
\hline Gender & .85 & $.41^{* * *}$ \\
\hline$F$ & & $50.22^{* * *}$ \\
$R^{2}$ & .17 & \\
Adj- $R^{2}$ & .17 \\
Durbin-Watson & 2.12 \\
\hline
\end{tabular}

Note. $N=256$. dummy variables: boys $=0$, girls $=1$.

*** $p<.001$.

결과는 Table 6 과 같다. 유아의 거친 놀이선호에 대해 사회인 구학적 변인인 유아의 성별 $(\beta=.41, p<.001)$ 이 $17 \%$ 의 설명력 을 나타냈다. $F$ 값은 50.22로 .001 수준에서 통계적으로 유의하 게 나타났다. 즉, 유아의 거친 놀이선호에 영향을 미치는 변인 으로는 성별만이 확인되어, 거친 놀이를 좋아하는 것이 남아 들의 특성임이 다시 한 번 분명하게 나타났다. 반면에, 어머니 가 놀이에 대해 형성한 신념이나 유아가 가정에서 놀이를 얼 마나 경험하는지는 거친 놀이에 대한 선호에 전혀 영향을 미 치지 않았다.

어머니의 놀이신념, 유아의 성별과 가정놀이빈 도가 유아의 조용한 놀이선호에 미치는 영향력

마지막으로, 어머니의 놀이신념과 유아의 성별 및 가정놀이빈
도가 조용한 놀이선호에 영향을 미치는지 알아보았다. 회귀분 석 결과는 Table 7과 같다. 유아의 조용한 놀이선호에 대해 유 아의 성별 $(\beta=.41, p<.001)$ 과 가정놀이빈도 $(\beta=.16, p<.01)$, 어 머니의 놀이신념 $(\beta=.13, p<.05)$ 이 모두 영향을 미치는 것으로 나타났다. 유아의 성별이 $18 \%$ 의 설명력을 보였고, 놀이 빈도 가 추가됨으로써 설명력이 $3 \%$ 증가한 $21 \%$ 가 되었으며, 어머 니의 놀이신념이 추가됨으로써 다시 $2 \%$ 증가한 총 $23 \%$ 가 되 었다. 이 결과는 여아가 남아보다 조용한 놀이를 더 선호하며, 유아가 가정에서 놀이를 더 자주하고, 어머니가 놀이에 대한 신념이 강할수록 유아가 조용한 놀이를 선호함을 보여주었다.

\section{논의 및 결론}

본 연구는 만 5세 유아를 대상으로 하고 그 어머니를 통해 질문 지 조사를 실시하여, 어머니의 놀이신념과 유아의 가정놀이빈 도가 유아의 유형별 놀이선호에 영향을 미치는지 살펴보고자 하였다. 이러한 영향력 분석의 타당성을 확인하기 위해 변인 간 의 상관관계부터 파악하였으며, 유아의 성별에 따라 가정놀이 빈도와 놀이선호에 차이가 있는지도 분석하였다. 본 연구를 통 해 얻은 결과를 중심으로 논의하며 결론을 내리고자 한다.

첫째, 가정놀이빈도에서 남아와 여아 간의 차이는 크지 않 으나, 구체적인 놀이의 종류에 따라 빈도에서 성차가 나타나 기도 한다. 여아들은 남아들보다 장난감/실물놀잇감 놀이, 가 장놀이, 미술놀이를 더 자주 하는 반면, 남아들은 블록놀이와 실외놀이를 여아들보다 유의하게 더 많이 하는 것으로 나타닜 다. 그리고 남아는 활동적 놀이, 거친 놀이를 더 선호하는 반

Table 7

Stepwise Regression Analyses of Mothers' Play Beliefs, Children's Gender and Play Frequency on Children's Preference for Quiet Play

\begin{tabular}{|c|c|c|c|c|c|c|}
\hline & & & Prefer & iet play & & \\
\hline & & & & & & \\
\hline & B & $\beta$ & B & $\beta$ & B & $\beta$ \\
\hline Play frequency & & & .18 & $.18^{* *}$ & .16 & $.16^{* *}$ \\
\hline Mothers' play belief & & & & & .32 & $.13^{*}$ \\
\hline $\operatorname{Adj}-R^{2}$ & & & & & & \\
\hline$\Delta R^{2}$ & & & & & & \\
\hline Durbin-Watson & & & & & & \\
\hline
\end{tabular}

Note. $N=256$. dummy variables: boys $=0$, girls $=1$.

${ }^{*} p<.05{ }^{* *} p<.01{ }^{* * *} p<.001$. 
면, 여아는 남아보다 조용한 놀이를 더 선호하는 것으로 나타 났다.

즉, 남아들은 시공간적 구성 작업과 관련된 블록놀이와 실 내를 벗어나 활동적으로 움직이며 노는 것을 더 자주 하는 반 면, 여아들은 실내에 앉아서 놀잇감을 조작하거나, 소품을 활 용하며 역할놀이 하기, 재료를 활용해 그리거나 만드는 활동, 그리고 학습과 연결되는 놀이 등을 더 자주 한다고 볼 수 있다. 그리고 유아들이 성별에 따라 선호하는 놀이 유형이 분명히 다르게 나타난 결과는 남아가 여아보다 몸을 거칠게 움직이면 서 노는 활동적인 신체 놀이를 더 많이 한다(Benenson, 1993; Dipietro, 1981; Humphreys \& Smith, 1984; H. B. Lee, 2008; Si Ja Lee \& Lim, 1998; Sook Jae Lee, 1998; Pellegrini, 1989, 1992) 는 결과들과도 일치한다.

본 연구의 결과를 통해 생물학적 측면에서 남아는 여아 보다 잠재된 신체적 에너지가 더 많아 활동적이고 거친 놀 이를 좋아하고, 여아는 놀잇감을 조작하거나 관계지향적인 (Benenson, 1993; Fromberg, 2002; M.-S. Kim et al., 2010; J.-Y. Lee \& Lee, 2008; Y. S. Lee \& Yoon, 2006; Lindsey \& Mize, 2001; McNeilly-Choque, Hart, Robinson, Nelson, \& Olsen, 1996; Pellegrini \& Perlmutter, 1989; Serbin et al., 1999) 조용한 놀이를 더 좋아하여, 놀이의 유형에 따른 선호도의 성차가 분명하게 나타남을 알 수 있었다. Miller와 Kuhaneck (2008)은 아동의 성 별과 함께, 특정 놀이가 요구하는 활동성 정도, 즉, 움직임의 양이 그 놀이를 선택하게 하는 기준이 된다고 하였다. 유아기 놀이의 이러한 성차는 사회화나 학습을 거쳐 나타나는 부분도 있겠지만(Martin, Eisenbud, \& Rose, 1995), 활동성이나 대 · 소 근육의 움직임과 관련된 측면은 생물학적 본성에 가깝다고 볼 수 있으므로, 이를 인정하는 훈육과 교육적 접근이 요구된다. 예를 들어, 유아교육기관의 대집단 생활 속에서, 또는 아파트 가 대부분인 주거환경에서 활동적이거나 거친 놀이에 몰입하 는 남아들에 대한 지나친 제한이 반복된다면 놀이 욕구가 충 족되지 못해 발달적으로 위험한 결과를 가져올 수도 있다.

둘째, 어머니의 놀이신념과 유아의 가정놀이빈도는 유아의 놀이선호와 부분적인 상관을 보였다. 활동적 놀이선호는 어머 니의 놀이신념과 전반적으로 정적 상관이 있었다. 그리고 조 용한 놀이선호는 어머니의 놀이신념 총합과 놀이 효용 인식, 가정에서의 놀이빈도, 그 중에서도 자유놀이빈도와 정적 상관 을 보였다. 그러나 유아의 거친 놀이선호는 어머니의 놀이신 념 및 유아의 가정놀이빈도 요인들과 상관이 없었다. 즉, 거친 놀이를 제외하고 활동적 놀이와 조용한 놀이에 대한 유아의 선호도는 어머니의 놀이신념 및 유아의 가정놀이빈도를 이루
는 요인들과 정적인 상관을 가짐을 확인할 수 있었다.

Y. Y. Park과 Kim (2011)의 연구에서는 어머니의 놀이 인식 수준이 높은 집단의 유아들이 신체적 활동성, 놀이 중 만족도, 놀이 참여도, 사교적 활동성이 모두 높게 나타난 바 있는데, 본 연구에서 드러난 상관과 일맥상통하는 면이 있다. 다만 거친 놀이라는 특정 유형은 일반적인 놀이와 다소 분리됨을 알 수 있었다. 어머니가 놀이에 대한 중요성을 높게 인식할 때 유아 의 놀이를 더 지지하고 격려해주며, 스스로도 자녀의 놀이에 더 적극적으로 참여하므로(Y. S. Kim, 1991; J. H. Park \& Han, 2007), 어머니의 놀이신념이 유아의 가정놀이빈도 및 놀이선 호와 직접 관련될 수 있다고 해석된다. 이와 같이, 어머니의 놀 이신념과 유아의 가정놀이빈도, 그리고 종류별 놀이선호 간에 부분적인 상관은 확인되었으나 그 방향성을 알 수는 없으므 로, 보다 구체적인 영향력 분석이 필요하다.

셋째, 놀이의 종류별로 유아의 선호도에 영향을 미치는 변 인들이 다르다. 먼저, 활동적 놀이의 선호에 대해서는 유아의 성별과 어머니의 놀이신념이 영향을 미치는 것으로 나타났다. 활동적 놀이선호에 대한 성별의 영향력이 확인된 것은 위의 차이 분석에서 나타난 결과를 더 강력하게 뒷받침해준다. 다 시 말해, 남아들이 여아들보다 활동적 놀이를 더 좋아함을 회 귀분석을 통해서도 증명했다고 할 수 있다. 그리고 어머니 놀 이신념의 영향력에 대한 결과는 부모의 놀이신념이 긍정적이 고 강할 경우에 유아의 신체적 자발성이 높다는 연구 결과 $(\mathrm{H}$. B. Lee, 2008; You \& Yoo, 2008)와 유사하다. 즉, 어머니가 놀이 의 가치와 효용을 인식하고, 스스로 유아와의 놀이에 즐겁게 참여하는 정도가 클 수록 유아가 활동적인 놀이를 더 좋아하 게 됨을 알 수 있다. 어머니가 놀이의 중요성이나 가치를 인식 하는 것에서 더 나아가 특히 유아와의 놀이에 직접 참여한다 는 것은 그 자체로 유아의 놀이를 인정하고 격려한다는 신호 가 되므로, 유아는 이러한 긍정적 피드백을 통해 놀이에 더 적 극적으로 참여하게 될 것이다.

다음으로, 유아의 성별만이 거친 놀이 선호에 영향을 미쳐 이 유형의 놀이가 남아들의 영역임을 보여주었다. 어머니의 놀이신념이나 유아의 가정놀이빈도는 전혀 영향을 미치지 않 았다. 따라서 유아가 거친 놀이를 좋아하는 것은 어머니의 심 리적 특성이나 가정에서의 경험보다는 생물학적인 특성이 설 명함을 알 수 있었다. 남아가 여아보다 거친 신체 놀이에 더 많 이 참여하고, 더 몰입하며, 더 즐거워한다는 연구 결과는 충분 히 축적되어 왔는데(Jeong \& Chung, 2016; Smith \& Boulton, 1990), 본 연구의 결과를 통해 거친 놀이 선호에 대한 성별의 영향력도 검증되었다. 이처럼 뚜렷한 놀이행동의 성차는 남아 
가 여아보다 에너지 소모가 많은 놀이를 선천적으로 선호하기 때문으로 보인다. 본 연구의 결과는 어머니의 놀이신념이 유아 의 활동적 놀이는 인정하나 거친 놀이까지는 포함하지 않으며, 유아가 가정에서 경험하는 놀이에도 거친 놀이는 별로 포함되 지 않음을 보여준다. 실제로 어머니나 여성 교사는 남아들의 거친 놀이를 이해하거나 격려해주지 못하는 경우가 많다. 게다 가 요즘 유아들은 공동주택이 일반화된 주거환경의 실내에서 거칠게 놀 수 있는 기회를 박탈당한다. 그러나 거친 놀이는 공 격성이나 폭력성을 나타내는 부정적 활동이 아닌, 축적된 신 체적 에너지를 발산시켜주고 유아의 자연스러운 발달을 증명 하는 활동이다(Jeong \& Chung, 2016; Pellegrini, 1989; Smith \& Boulton, 1990). 따라서 유아의 놀이 발달과 성차에 대한 부모 교육이 도움이 될 것이며, 가정과 교육기관에서 활동수준이 높 은 실내·외 놀이를 지원하는 것이 좋다고 본다.

마지막으로, 유아의 성별과 가정놀이빈도, 어머니 놀이신 념은 조용한 놀이의 선호에 공통적으로 영향을 미치는 것으로 나타났다. 조용한 놀이는 활동적 놀이, 거친 놀이와 달리 여아 들이 더 많이 선호하는 것으로 나타난 유형이다. T. S. Choi와 Jo (2008)는 여아가 남아보다 정서적 놀이성이 높고, 다른 사 람과 상호작용하며 노는 사회적 놀이성과 혼자 하는 놀이 성 향이 모두 높음을 보여주었다. 이러한 차이가 여아들의 조용 한 놀이선호를 설명함을 알 수 있다. 한편, 조용한 놀이선호는 유일하게 가정놀이빈도, 즉, 유아가 가정에서 얼마나 자주 노 는지가 영향을 미친 유형이다. 즉, 가정에서 놀이하는 경험이 양적으로 풍부한 유아가 ‘조용한 테이블 활동', '미술과 손으 로 하는 공예', '상상 놀이'와 같은 조용한 놀이를 선호하는 것 이 증명된 것이다. 가정놀이빈도가 조용한 놀이의 선호만을 설명하는 원인으로는 본 연구의 가정놀이빈도 측정에서 실외 놀이와 협동놀이도 포함되어 있긴 했지만, 대체적으로 실내에 서 이루어지는 조용한 놀이의 종류가 더 많이 포함되어 있었 던 것을 들 수 있겠다. 조용한 놀이는 일반적으로 앉아서 놀잇 감을 조작하거나, 소규모의 또래들과 언어적 상호작용을 하 고 소근육을 활용하며 함께 노는 유형으로, 실내에서 가장 많 이 일어나는 대표적 놀이이다. 활동적 놀이, 거친 놀이가 주로 실외에서 대근육을 활용하여 이루어지므로 성인의 통제가 요 구되거나 크고 작은 부상 또는 또래 간 갈등이 잦은 것과 비해, 조용한 놀이는 부정적 결과가 뒤따르는 가능성이 적고 부모와 교사 등 보호자들이 유아들의 바람직한 행동으로 인식하는 정 도가 높다. 유아의 성별을 통제하고도 가정에서의 놀이빈도가 조용한 놀이선호에 영향을 미치므로, 유아들이 가정에서 충분 히 노는 경험을 할 수 있도록 지원해야 할 것이다.
그런데 현재 우리사회의 유아들은 과거에 비해 가정에서 놀이하는 시간이 줄어들었다. 출산율 저하로 가정 당 자녀수 가 줄어들고, 영유아기부터 다양한 교육경험에 몰입하다보 니 가정에서 자유롭게 형제나 친구와 놀기 힘들어진 것이다. 또래 간의 놀이를 할 수 없는 외동 유아나 형제간의 나이 차 가 큰 경우 가정에서 혼자놀이가 이루어지고(S.-S. Lee \& Nam, 2016), 사교육을 통해 유아에게 놀이 대상과 놀이의 기회를 제 공하는(Min \& Bae, 2014) 현실이다. 놀이는 유아의 발달에 필 수적이며, 원할 때 원하는 방식으로 자발적으로 이루어질 때 특히 효과적이므로(J.-N. Kim, 2002), 가정에서 유아가 자유롭 게 놀 수 있는 환경과 기회를 충분히 제공해야 하며, 어머니 등 성인도 적극적으로 놀이에 함께 참여함으로써 더욱 풍부한 놀 이경험을 만들어주어야 할 것이다.

이상의 회귀분석 결과를 종합하면, 놀이 유형별 선호는 예 측 요인이 차별화되어, 활동적 놀이는 성별과 어머니의 놀이 신념이 영향을 미치고, 거친 놀이는 성별만이, 그리고 조용한 놀이는 성별, 가정놀이빈도, 어머니의 놀이신념이 각각 영향 력을 미치는 것으로 나타났다. 이를 통해 유아의 놀이는 유형 별로 관련 변인이 크게 다름을 알 수 있었다.

본 연구의 제한점을 바탕으로 향후 연구의 방향성을 제언 한다면 다음과 같다. 첫째, 본 연구는 수도권에 위치한 유치원 과 어린이집에 재원 중인 만 5세 유아와 어머니를 대상으로 이 루어졌기 때문에 지역, 환경에 대한 한계가 있으며, 연구 결과 를 모든 유아를 대상으로 일반화하기는 어렵다. 후속 연구에 서는 다양한 지역, 환경을 고려한 연구가 필요할 것으로 본다. 둘째, 질문지 조사를 실시한 본 연구는 어머니의 놀이신념, 유 아의 가정놀이빈도와 유아의 놀이선호를 모두 어머니의 인식 에 따라 측정하였으므로 주관적 편의 가능성이 있다. 또한 유 아의 가정놀이경험의 질적 측면은 고려하지 않고 빈도라는 양 적 측면만 고려하였는데, 객관성을 높이면서 질적 측면도 담 아내기 위해 어머니, 유아와의 면접 및 관찰을 통해 가정에서 의 놀이경험을 측정할 필요가 있다. 유아의 놀이선호 역시 유 아를 직접 면접 및 관찰함으로써 더욱 정확한 측정이 가능할 것이다.

이러한 제한점에도 불구하고 본 연구는 어머니의 놀이신념 과 유아의 가정놀이빈도가 종류별 놀이선호에 미치는 영향력 을 검증하였다는 데 의미를 부여할 수 있다. 또한 유아의 놀이 에서 나타나는 성차에 대한 시사점을 도출하였고, 어머니의 심리적 특성인 놀이신념과 계량화한 가정놀이빈도가 유아의 놀이선호에 직접적인 영향을 미침을 보여주었다. 이 연구의 결과는 유아의 놀이에 대해 상이한 가치 인식으로 인해 어려 
움을 느끼는 가정과 유아교육기관을 위해 놀이의 중요성에 대 한 근거자료로 활용될 수 있을 것으로 기대한다.

\section{Notes}

This article is a part of the first author's master's thesis submitted in 2017.

\section{Conflict of Interest}

No potential conflict of interest relevant to this article was reported.

\section{References}

\section{In English}

Benenson, J. F. (1993). Greater preference among females than males for dyadic interaction in early childhood. Child Development, 64(2), 544-555. doi:10.1111/j.1467-8624.1993.tb02927

Chudacoff, H. P. (2007). Children at play: An American history. New York: New York University Press.

Cicirelli, V. G. (1985). Sibling relationships throughout the life cycle. In L. L'Abate (Ed.), The handbook of family psychology and therapy (pp. 177-214). Chicago, IL: The Dorsey Press.

Colwell, M. J., \& Lindsey, E. (2005). Preschool children's pretend and physical play and sex of play partner: Connections to peer competence. Sex Roles, 52(7), 497-509. doi:10.1007/ s11199-005-3716-8

DiPietro, J. A. (1981). Rough and tumble play: A function of gender. Development Psychology, 17(1), 50-58.

Fabes, R. A., Martin, C. L., \& Hanish, L. D. (2003). Young children's play qualities in same-, other-, and mixed-sex peer groups. Child Development, 74(3), 921-932. doi:10.1111/14678624.00576

Finegan, J. K., Niccols, G. A., Zacher, J. E., \& Hood, J. E. (1991). The play activity questionnaire: A parent report measure of children's play preferences. Archives of Sexual Behavior, 20(4), 393-408. doi:10.1007/BF01542619

Fisher, K. R., Hirsh-Pasek, K., Golinkoff, R. M., \& Gryfe, S. G. (2008). Conceptual split? Parents' and experts' perceptions of play in the 21st century. Journal of Applied Developmental Psychology, 29(4), 305-316. doi:10.1016/j.appdev.2008.04.006

Fogle, L. M. (2003). Parent beliefs about play: Relations with parent-child play interactions and child peer play competence (Unpublished doctoral dissertation). University of North Carolina, NC.

Fromberg, D. P. (2002). Play and meaning in early childhood education. Boston: Allyn and Bacon.

Hong, J. C., Hwang, M. Y., Lu, C. H., Cheng, C. L., Lee, Y. C., \& Lin, C. L. (2009). Playfulness-based design in educational games: A perspective on an evolutionary contest game. Interactive Learning Environments, 17(1), 15-35. doi:10.1080/10494820701483615

Humphreys, A. P., \& Smith P. K. (1984). Rough-and-tumble in preschool and playground. In P. K. Smith (Ed.), Play in animals and humans. Oxford: Bassil Black well.

Isenberg, J. P., \& Quisenberry, N. L. (1988). Play: A necessity for all children. Childhood Education, 64(3), 138-145. doi:10.1 080/00094056.1988.10521522

Johnson, J. E., Chistie, J. F., \& Wardle, F. (2005). Play, development and early education. Boston, MA: Pearson Education.

Lindsey, E. W., \& Mize, J. (2001). Contextual differences in parent-child play: Implication for children's gender role development. Sex Roles, 44(3), 155-176. doi:10.1023/ A: 1010950919451

Martin, C. L., Eisenbud, L., \& Rose, H. (1995). Children's genderbased reasoning about toys. Child Development, 66(5), 1453-1471. doi:10.1111/j.1467-8624.1995.tb00945.x

Martin, C. L., \& Fabes, R. A. (2001). The stability and consequences of young children's same-sex peer interaction. Development Psychology, 37(3), 431-446. doi:10.1037/00121649.37.3.431

McNeilly-Choque, M., Hart, C., Robinson, C., Nelson, L., \& Olsen, S. (1996). Overt and relational aggression on the playground: Correspondence among different informants. Journal of Research in Childhood Education, 11(1), 47-67. doi:10.1080/02568549609594695

Miller, E., \& Kuhaneck, H. (2008). Children's perceptions of play experiences and play preferences: A qualitative study. American Journal of Occupational Therapy, 62(4), 407-415. doi:10.5014/ajot.62.4.407

Pellegrini, A. D. (1989). Children's rough-and-tumble play: Issues in categorization and function. Educational Policy, 3(4), 389-400. doi:10.1177/0895904889003004006

Pellegrini, A. D. (1992). Preference for outdoor play during early adolescence. Journal of Adolescence, 15(3), 241-254. doi:10.1016/0140-1971(92)90028-4

Pellegrini, A. D., \& Buorklund, D. F. (2004). The ontogeny and phylogeny of children's object and fantasy play. Human Nature, 15(1), 23-43. doi:10.1007/s12110-004-1002-z

Pellegrini, A. D., \& Perlmutter, J. C. (1989). Classroom contextual effects on children's play. Development Psychology, 25(2), 289-296. doi:10.1037/0012-1649.25.2.289

Playwork Principles Scrutiny Group. (2005). Playwork principles 
[Web page]. Retrieved June 25, 2013 from http://www. skillsactive.com

Pollock, N., Stewart, D., Law, M., Sahagian-Whalen, H. S., \& Toal, C. (1997). The meaning of play for young people with physical disabilities. Canadian Journal of Occupational Therapy, 64(1), 25-31. doi:10.1177/000841749706400105

Rogers, C. S., Impara, J. C., Frary, R. B., Harris, T., Meeks, A., Semanic-Lauth, S., \& Reynolds, M. (1998). Measuring playfulness: Development of the child behaviors inventory of playfulness. In S. Reifel (Vol. Ed.) \& M. C. Duncan, G. Chick, \& A. Aycock (Series Eds.), Play \& Culture Studies: Vol. 1. diversions and divergences in fields of play (pp. 151168). Greenwich, CT: Ablex.

Serbin, A., Bohlin, G., \& Berlin, L. (1999). Sex differences in 1-, 3-, and 5-year-olds' toy-choice in a structured play-session. Scandinavian Journal of Psychology, 40(1), 43-48. doi:10.1111/14679450.00096

Smith, P. K., \& Boulton, M. (1990). Rough-and-tumble play, aggression and dominance: Perception and behavior in children's encounters. Human Development, 33, 271-282. doi: $10.1159 / 000276524$

The Henry J. Kaiser Family Foundation. (2005). A teacher in the living room?: Educational media for babies, toddlers and preschoolers. Retrieved from https://kaiserfamilyfoundation. files.wordpress.com/2013/01/7427.pdf

\section{In Korean}

Byun, H. Y., \& Chung, K. S. (2008). A study on the interaction of peer play with social and cognitive play forms infant relationship. Child Educare Research, 14, 35-49. Retrieved from http://www.riss.kr/link?id=A76523837

Choi, E. A. (2005). Study on the relationships of young children's temperament, mother's mother-child interaction behaviors and children's playfulness (Master's thesis). Retrieved from http:// www.riss.kr/link?id=T9766228

Choi, M. S., \& Kim, J. H. (2006). The effect of playfulness on the social skills of young children: A study of gender differences. Korean Journal of Child Studies, 27(4), 103116. Retrieved from http://childstudies.org/current/index. php? vol $=27 \&$ no $=4$

Choi, T. S., \& Cho, M. J. (2008). A study on playfulness of school-aged children: Gender, age, and types of playfulness. Korean Journal of Play Therapy, 11(1), 17-30. Retrieved from http://www.riss.kr/link?id=A5081263

Eom, J. A. (2001). Exploring the direction in linking play with early childhood education. The Journal of Korea Open Association for Early Childhood Education, 5(3), 1-25. Retrieved from http://www.riss.kr/link?id=A75437556

Jeong, N. Y., \& Chung, K. S. (2016). Differences in emotional intelligence and prosocial behavior to preschooler's participation level of rough-and-tumble play. Teacher Education Research, 55(1), 70-82. Retrieved from http://www.riss.kr/ link?id=A101869486

Jin, M.-H., \& Seo, H.-S. (2004). Sex-typed disposition in play preference and play type by age of children and the relationship between sex-typed play and sex role stereotype. Korean Journal of Early Childhood Education, 24(3), 141-162. Retrieved from http:// www.riss.kr/link?id=A99534678

Kim, J. J., Kim, J. H., \& Shin, Y. L. (2002). 125 toys suitable for infants. Seoul: Changjisa.

Kim, J.-N. (2002). Children's rights to play: A philosophical justification. Journal of Korean Council for Children \& Rights, 6(1), 31-46. Retrieved from http://www.riss.kr/ link?id=A77015622

Kim, M.-S., Yoo, J.-Y., Lee, M.-J., \& Cho, H.-R. (2010). A study on young children's free play behaviors at the same-aged classrooms: The relationship to learning area, play mate and playfulness. The Journal of Korea Open Association for Early Childhood Education, 15(3), 75-98. Retrieved from http:// www.riss.kr/link?id-A99891607

Kim, Y. S. (1991). The study on the relationship between mothers perception about the thinking of the importance of play and children's play activities (Master's thesis). Retrieved from http://www.riss.kr/link?id-T906907

Korea Institute of Child Care and Education. (2014). For happiness of infants and toddlers sufficient leisure time must be guaranteed. Yugajeongchaeek Brief, (24), 1-4. Retrieved from http://www.kicce.re.kr

Lee, H. B. (2008). Parent beliefs about play: Effects on children's playfulness and communication ability (Master's thesis). Retrieved from http://www.riss.kr/link?id=T11390306

Lee, J.-Y., \& Lee, K.-O. (2008). Young children's rough and tumble play, peer competence and peer popularity. Journal of Korea Open Association for Early Childhood Education, 13(3), 93112. Retrieved from http://www.riss.kr/link?id=A99891398

Lee, S. J. [Si Ja]., \& Lim, M. H. (1998). A study on rough and tumble plays: focused on 6-year-olds' outdoor plays at kindergartens. Korean Journal of Educational Research, 36(3), 255-279. Retrieved from http://www.riss.kr/ link?id=A99796727

Lee, S. J. [Sook Jae]. (1998). Rough-and-tumble play and social competence in preschool children. Korean Journal of Child Studies, 19(1), 131-140. Retrieved from http://childstudies. org/current/index.php?vol=19\&no=1

Lee, S.-S., \& Nam, K.-C. (2016). Analysis of mothers' discourse on young children's right to play. The Journal of Child Education, 25(4), 293-316. Retrieved from http://www.riss. $\mathrm{kr} / \mathrm{link}$ ? id=A102393257

Lee, Y. S., \& Yoon, J. (2006). A different peer culture in preschool 
classroom according to sex. Journal of Early Childhood Education, 15(2), 177-194. Retrieved from http://www.riss. $\mathrm{kr} /$ link?id=A75752466

Min, S.-O., \& Bae, J.-H. (2014). Mothers' perceptions of and experiences about children's private education. The Journal of Child Education, 23(4), 263-285. Retrieved from http:// www.riss.kr/link?id=a100177917

Park, G. H. (2011). Parent awareness of the relationship between play and education and infant play time at home (Unpublisehd master's thesis). Duksung Women's University, Seoul. Seoul, Korea.

Park, H.-S. (2003). The comparison of the awareness of children's play between kindergarten teachers and parents. The Korea Association of Child Care and Education, 35, 221-240. Retrieved from http://www.riss.kr/link?id=A45027751

Park, J. H., \& Han, S. S. (2007). The relationship between children's playfulness and the home environment. Korean Journal of Education and Care, 7(2), 55-72. Retrieved from http://www.riss.kr/link?id=A76443955

Park, K.-D. (2005). An investigation into the progressive characteristics of gross and fine motor skill development in childhood (Doctoral dissertation). Retrieved from http:// www.riss.kr/link?id=T9808727

Park, Y. Y., \& Kim, L. J. (2011). Childhood play experience, play-related perceptions and child perception of mothers of children between preschool through third grade and their mother-child play condition. Korean Journal of Play Therapy, 14(2), 37-56. Retrieved from http://www.riss.kr/ link?id=A82590440

Seo, J. S., Lee, S. G., \& Park, D. G. (2009). A study of validation of a parent report measure of children's play preferences. The Journal of Korea Open Association for Early Childhood, 14(1), 61-76. Retrieved from http://www.riss.kr/ link?id=A99891472

You, M., \& Yoo, M. S. (2008). The effects of maternal beliefs about play and emotional expressiveness on children's playfulness. Korean Journal of Play Therapy, 11(4), 53-63. Retrieved from http://www.riss.kr/link?id=A75698062

\section{ORCID}

Jun Hee Han http://orcid.org/0000-0003-3225-6548

Na Ya Choi http://orcid.org/0000-0001-9189-9370

Received March 27, 2017

Revision received April 22, 2017

Accepted April 23, 2017 